\title{
Activation of Metabotropic Glutamate Receptor Subtype mGluR1 Contributes to Post-Traumatic Neuronal Injury
}

\author{
Alexey Mukhin, ${ }^{1}$ Lei Fan, ${ }^{1}$ and Alan I. Faden ${ }^{2}$ \\ ${ }^{1}$ Department of Neurology and the Institute for Cognitive and Computational Sciences, and ${ }^{2}$ Departments of Neurology \\ and Pharmacology and the Institute for Cognitive and Computational Sciences, Georgetown University Medical Center, \\ Washington, DC 20007-2197
}

The role of phospholipase C-coupled (group I) metabotropic glutamate receptors (mGluR1 and mGluR5) in post-traumatic neuronal injury was examined using rat in vivo and in vitro models. Traumatic injury to mixed neuronal/glial cultures induced phosphoinositide hydrolysis and caused neuronal death. Pharmacological blockade of group I receptors significantly reduced these effects in vitro and decreased neurological deficits as well as neuronal loss produced by traumatic brain injury in vivo. In contrast, activation of group I receptors by a specific agonist in vitro exacerbated post-traumatic neuronal death in a dose-dependent manner. Antisense oligodeoxynucleotide di- rected to mGluR1, but not to mGluR5, was neuroprotective in vitro, although each oligodeoxynucleotide reduced the respective receptor-stimulated accumulation of inositol phosphates to a similar degree. Together, these findings suggest that activation of mGluR1 contributes to post-traumatic neuronal injury and that mGluR1 antagonists may have therapeutic potential in brain injury.

Key words: antisense oligodeoxynucleotides; brain trauma; metabotropic glutamate receptors; neuronal injury; neuroprotection; phosphoinositide hydrolysis
Increased glutamate release and activation of ionotropic glutamate receptors have been implicated in the pathophysiology of traumatic brain (Hayes et al., 1988; Faden et al., 1989; McIntosh et al., 1990) and spinal cord injuries (Faden and Simon, 1988; Wrathall et al., 1992). Metabotropic glutamate receptors participate broadly in the regulation of glutamate neurotransmission (Schoepp and Conn, 1993), yet their role in post-traumatic CNS injury has been largely unexplored.

Metabotropic glutamate receptors (mGluR) are coupled through G-proteins to second-messenger systems (Hollman and Heinemann, 1994; Pin and Duvoisin, 1995). Molecular cloning techniques have elucidated eight mGluR subtypes to date, some of which include alternately spliced variants (Hollman and Heinemann, 1994; Pin and Duvoisin, 1995). mGluR have been divided into three groups based on sequence homology: group I includes mGluR1 and mGluR5; group II includes mGluR2 and mGluR3; and group III includes mGluR4, mGluR6, mGluR7, and mGluR8 (Pin and Duvoisin, 1995). These three groups are further differentiated by their respective signal transduction mechanisms: group I receptors stimulate phospholipase C (PLC), leading to phosphoinositide (PI) hydrolysis and intracellular $\mathrm{Ca}^{2+}$ mobilization, whereas group II and group III receptors are coupled to the inhibition of adenylyl cyclase (Saugstad et al., 1994; Pin and Duvoisin, 1995).

There has been limited research to address a possible role for mGluR in modulating neuronal death after various nontraumatic

\footnotetext{
Received April 2, 1996; revised June 28, 1996; accepted July 19, 1996.

This work was supported in part by grants from the Centers for Disease Control (CCR306634) and National Institutes of Health (NS27849) to A.I.F. We thank Randyll Goodnight for technical assistance, and Linda Powell and Elizabeth Wellner for editorial assistance in the preparation of this manuscript.

Correspondence should be addressed to Dr. Alan I. Faden, Georgetown University Medical Center, NW103 Med. Dent. Bldg., 3900 Reservoir Road NW, Washington, DC 20007-2197.

Copyright (C) 1996 Society for Neuroscience $0270-6474 / 96 / 166012-09 \$ 05.00 / 0$
}

insults. To a certain extent, groups I and II mGluR appear to have contrasting actions. Group I receptors may potentiate neuronal excitation and excitotoxicity (Buisson and Choi, 1995; Pin and Duvoisin, 1995; Buisson et al., 1996), possibly through positive modulation of NMDA receptor activity (Fitzjohn et al., 1996). Group II receptors may exert a protective effect (Bruno et al., 1994; Buisson and Choi, 1995), possibly through presynaptic inhibition of glutamate release (Watkins and Collingridge, 1994; Pin and Duvoisin, 1995). Because of these apparently opposing actions, and the fact that more discriminating agonists/antagonists are not yet available, it is not surprising that data have been less than conclusive with regard to the role of mGluR in neuronal death. Indeed, the cyclic glutamate analog $1 S, 1 R-1$ aminocyclopentane-1,3-dicarboxylic acid ( $1 S, 1 R$-ACPD), which is an agonist at both group I and group II receptors, has been reported in various studies to either contribute to or protect against cell death (Koh et al., 1991; Chiamulera et al., 1992; McDonald and Schoepp, 1992; Sacaan and Schoepp, 1992; Siliprandi et al., 1992; Birrell et al., 1993; McDonald et al., 1993).

The synthesis of phenylglycine derivatives has permitted differentiation of the activity of various metabotropic receptor groups through comparison of the activities of selected compounds (Watkins and Collingridge, 1994). However, differentiation of receptor subtypes within groups has remained problematic (Saugstad et al., 1995).

In the present studies, rat in vitro and in vivo trauma model systems were both used to investigate the role of group I mGluR in mediating post-traumatic neuronal injury. We used (1) metabotropic receptor agonists and antagonists to elucidate the role of group I receptors in secondary injury, and (2) antisense oligodeoxynucleotides (AS ODN) directed to group I receptor subtypes to compare or contrast the neuroprotective roles of mGluR1 and mGluR5. 


\section{MATERIALS AND METHODS}

Mixed neuronal/glial cultures. Sprague Dawley pregnant rats were obtained from Taconic Farms (Germantown, NY). Neocortex from 17- to 18-d-old embryos was dissociated, and cell suspension $\left(5 \times 10^{5} \mathrm{cells} / \mathrm{cm}^{2}\right)$ was seeded on top of confluent glial cultures $10 \mathrm{~d}$ in vitro (DIV). To prepare glial cultures, dissociated neonatal (1-2 d old) rat neocortex was seeded in 96-well Primeria plates (Falcon, Lincoln Park, NJ) at a density of 0.5 hemisphere/plate. In each case, the cortex was dissociated with a serological pipette in HBSS without magnesium or calcium, supplemented by $10 \mathrm{~mm}$ HEPES, $\mathrm{pH} 7.0$, and $1 \mathrm{~mm}$ sodium pyruvate. The protocol for maintaining culture and media composition is detailed by Regan and Choi (1994). EBSS and HBSS were purchased from Mediatech (Herndon, VA); HEPES, glutamine, and glucose were from Biofluids (Rockville, MD); epidermal growth factor was from Life Technologies (Grand Island, NY); all other chemicals were procured from Sigma (St. Louis, MO).

In vitro trauma model. Our in vitro trauma model is based somewhat on the murine model developed previously by Choi and colleagues (Tecoma et al., 1989; Regan and Choi, 1994), which examined the role of ionotropic glutamate receptors in secondary injury using mixed neuronal/glial cultures. In the Regan and Choi model, injury is delivered by needlescoring a grid of eight parallel cuts, crossed by eight perpendicular cuts in each well of 24-well tissue culture plates. In our model, trauma is delivered by a specially designed punch: this device consists of 28 stainless steel blades joined together, which produce 28 parallel cuts $1.2 \mathrm{~mm}$ in length uniformly distributed through the cell layer at $0.5 \mathrm{~mm}$ intervals in each well of a 96-well tissue culture plate. Cells that are located directly under the blades are damaged. Because the release of lactate dehydrogenase (LDH) from initially damaged cells is washed out after a $30 \mathrm{~min}$ incubation period, our obtained LDH values appear to reflect secondary injury. Sixteen to eighteen hours after injury, we observed death in up to 60 percent of total neurons. This paradigm was used in all of our studies, except those that examined the group I mGluR agonist $R, S-3,5-$ dihydroxyphenylglycine (DHPG). For the latter experiments, a lower level of injury was required to assess possible exacerbation of traumainduced injury. In these experiments, trauma was delivered by a circular punch that produced a circular cut with a $4 \mathrm{~mm}$ diameter in the cell layer. After $16 \mathrm{hr}$, this injury caused death in up to $25 \%$ of neurons.

The advantages of our model include a high reproducibility and consistency of injury across the different wells, and the convenience and ability to perform many replications over a short period of time (up to 20 per min). In our model, as in that described previously (Tecoma et al., 1989; Regan and Choi, 1994), secondary cell death can be largely prevented by the addition of the NMDA receptor antagonist $5 R, 10 S-(+)-5-$ methyl-10,11-dihydro-5H-dibenzo[a,d]cyclohepten-5,10-imine (MK-801) (Mukhin and Faden, 1995), but 6-nitro-7-sulfamoylbenzo[f ]quinoxaline2,3-dione (NBQX), which is an antagonist of AMPA/kainate receptors, exerts no neuroprotective effect (our unpublished data).

Before injury, neuronal/glial cultures (17-19 DIV) were transferred to HEPES salt solution (120 mM NaCl, $5.4 \mathrm{~mm} \mathrm{KCl}, 0.8 \mathrm{~mm} \mathrm{MgCl}_{2}, 1.8 \mathrm{~mm}$ $\mathrm{CaCl}_{2}, 15 \mathrm{~mm}$ glucose, $15 \mathrm{~mm}$ HEPES, final $\mathrm{pH}$ 7.4) and incubated at $37^{\circ} \mathrm{C}$ for $30 \mathrm{~min}$ in the presence or absence of (+)- $\alpha$-methyl-4carboxyphenylglycine (MCPG), $(S)$-4-carboxyphenylglycine (4CPG), or $R, S$-3,5-dihydroxyphenylglycine (DHPG). MCPG, 4CPG, and DHPG were obtained from Tocris Cookson (St. Louis, MO). After injury, cells were incubated at $37^{\circ} \mathrm{C}$ for $30 \mathrm{~min}$ and washed five times $(>1000$-fold dilution) with growth medium ( $25 \mathrm{~mm}$ glucose, $1.0 \mathrm{~mm}$ glutamine, $25 \mathrm{~mm}$ HEPES, pH 7.2, $1 \%$ antibiotic-antimycotic in MEM EBSS). Cultures were then incubated in $5 \% \mathrm{CO}_{2}$ for $16-18 \mathrm{hr}$ at $37^{\circ} \mathrm{C}$ before assessment of injury. Control (uninjured) cultures (sister cultures from the same plate) were treated, i.e., washed, incubated (in the presence of agonist or antagonist, as required), and analyzed, using the same methods as for injured cultures.

Neuronal death was assessed by phase-contrast microscopy, trypan blue staining, and LDH assay. In our preliminary studies and those of Regan and Choi (1994), injury-induced LDH release $18 \mathrm{hr}$ after injury is highly correlated to the number of nonviable neurons. Therefore, in our present experiments we quantitated neuronal death by measuring LDH efflux into the medium.

LDH measurement. LDH activity was measured at room temperature using a modification of the method described by Amador et al. (1963). A volume of $75 \mu \mathrm{l}$ of culture medium was transferred to a 96-well microplate. A volume of $200 \mu \mathrm{l}$ of $\mathrm{LDH}$ assay reagent $(5 \mathrm{~mm} \beta-\mathrm{NAD}, 25 \mathrm{~mm}$ lactic acid, $0.03 \%$ BSA, $100 \mathrm{~mm}$ Tris, final $\mathrm{pH} 8.45$ ) was then rapidly added to each sample. Increases in optical density at $340 \mathrm{~nm}$ were measured at $10 \mathrm{sec}$ intervals for $6 \mathrm{~min}$ using a Ceres 900 microplate reader (Biotek Instruments, Winooski, VT). Lyophilized serum (Accutrol) served as the LDH standard. Background LDH levels were estimated in the control (uninjured) cultures and subtracted from the values obtained after experimental injury. Results are expressed as percentage of LDH release observed after injury without any treatment. All reagents, including standard serum, were procured from Sigma.

Phosphoinositide (PI) hydrolysis. PI hydrolysis was measured in mixed neuronal/glial cultures (17-20 DIV), incubated overnight with $0.1 \mathrm{mCi} /$ well myo- $\left[{ }^{3} \mathrm{H}\right]$ inositol (45 Ci/mmol, DuPont NEN, Boston, MA). Before injury, cells were washed three times with HEPES salt solution and incubated at $37^{\circ} \mathrm{C}$ for $30 \mathrm{~min}$ in the presence or absence of $500 \mu \mathrm{M}$ MCPG. Five minutes after addition of $20 \mathrm{~mm} \mathrm{LiCl}$, cells were injured and incubated at $37^{\circ} \mathrm{C}$. In $1 S, 3 R$-ACPD stimulation studies, cells were washed as above and preincubated at $37^{\circ} \mathrm{C}$ for $30 \mathrm{~min}$, and $20 \mathrm{~mm} \mathrm{LiCl}$ was added simultaneously with $500 \mu \mathrm{M} 1 S, 3 R$-ACPD (Tocris Cookson). Thirty minutes after injury or addition of $1 S, 3 R$-ACPD, incubation medium was aspirated and inositol phosphates were extracted by $0.1 \mathrm{M} \mathrm{HCl}$ containing $2 \mathrm{mM} \mathrm{CaCl}_{2}$. As detailed by Berridge et al. (1982), after separation on anion exchange columns (AG 1-X8, Bio-Rad, Hercules, CA), accumulated $\left[{ }^{3} \mathrm{H}\right]$ inositol phosphates were measured using a liquid scintillation counter (LS 6500, Beckman Instruments, Fullerton, CA).

AS ODN treatment. After $14 \mathrm{DIV}$, mixed neuronal/glial cultures were maintained in serum-free medium ( $25 \mathrm{~mm}$ glucose, $1.0 \mathrm{~mm}$ glutamine, 25 mM HEPES, pH 7.2, antibiotic-antimycotic, and MEM EBSS), and supplemented by $\mathrm{N} 2$ supplement (Life Technologies) in the absence (control) or presence of $2 \mu \mathrm{M}$ of appropriate ODN. Fresh ODN (up to 2 $\mu \mathrm{M})$ was added every $24 \mathrm{hr}$ for $5 \mathrm{~d}$. Antisense ODN (5'CCGGACCATTGTGGCGAA-3') directed to mGluR1 is complementary to the sequence region that begins with -9 and ends with +9 nucleotide (Masu et al., 1991). Position +1 corresponds to the A nucleotide in the first ATG codon. Sense ODN is 5'-TTCGCCACAATGGTCCGG-3', and missense ODN is $5^{\prime}$-CCGGAGCATAGTGGGGAA-3'. Antisense ODN directed to mGluR5 (5'-AGAAGGACCATTTTAGGA- $3^{\prime}$ ) is complementary to regions from -7 up to +11 (Abe et al., 1992). In this instance, sense ODN is $5^{\prime}$-TCCTAAAATGGTCCTTCT-3' and missense ODN is 5'-AGAAGCACCATATTACGA$3^{\prime}$. Oligodeoxynucleotides used in all our studies were obtained from Bio-Synthesis (Lewisville, TX) as phosphorothioate derivatives.

Immunoblot analysis. Neuronal/glial cultures (17-19 DIV) from 8 wells of the 96-well plate were collected in $1 \mathrm{ml}$ of ice-cold $10 \mathrm{~mm}$ Tris- $\mathrm{HCl}$ buffer, $\mathrm{pH}$ 7.4, containing $100 \mu \mathrm{M}$ phenylmethylsulphonyl fluoride (Sigma) and lysed by freezing and thawing. The membrane suspension was centrifuged at $14,000 \times g$ for $10 \mathrm{~min}$. The pellets were washed twice in the same buffer, and protein concentration was measured by Bio-Rad Protein Assay using bovine serum albumin as standard. Eight micrograms of membrane protein were separated by SDS-PAGE in $7.5 \%$ acrylamide and transferred onto Hybond-PVDF membrane (Amersham, Arlington Heights, IL). Immunostaining was done with primary affinity-purified rabbit polyclonal antibodies to the $\mathrm{C}$ terminus of $\mathrm{mGluR} 1 \alpha$ (Chemicon, Temecula, CA; dilution $2.5 \mu \mathrm{g} / \mathrm{ml}$ ) and to the C terminus of mGluR5 (Upstate Biotechnology, Lake Placid, NY; dilution $1 \mu \mathrm{g} / \mathrm{ml}$ ). Signals were detected using enhanced chemoluminescence (ECL) Western blotting detection system (Amersham).

Traumatic brain injury (TBI) in vivo. Male Sprague Dawley rats $(400 \pm$ $25 \mathrm{gm}$, Harlan, Indianapolis, IN) were anesthetized with sodium pentobarbital (Abbott Laboratories, North Chicago, IL; $70 \mathrm{mg} / \mathrm{kg}$, i.p.) and subjected to lateral fluid percussion-induced brain trauma. In this model, a fluid wave is delivered to the extradural space over the left parietal cortex, transiently deforming the underlying brain. Details are provided by Faden et al. (1989) and McIntosh et al. (1989). This model simulates many features of human concussive brain injury and has been well defined in terms of its behavioral, biochemical, and histological outcomes (Faden et al., 1989; McIntosh et al., 1989; Sun and Faden, 1995b).

In central administration studies, vehicle ( $10 \mu \mathrm{l}$ of $25 \mathrm{~mm}$ Tris, $\mathrm{pH}$ 7.4, in normal saline, $n=12$ animals $)$ or $R, S$-MCPG $(0.5 \mu \mathrm{mol}$ in $10 \mu \mathrm{l}$ of 25 mM Tris, $\mathrm{pH} 7.4$, in normal saline, $n=9$ animals) was injected into the lateral ventricle $15 \mathrm{~min}$ before and $1 \mathrm{hr}$ after percussion-induced TBI of 2.8 atmospheres (atm). In systemic administration studies, vehicle $(0.4 \mathrm{ml}$ of $10 \mathrm{~mm}$ Tris, $\mathrm{pH} 7.4$, in normal saline, $n=15$ animals) or $R, S$-MCPG

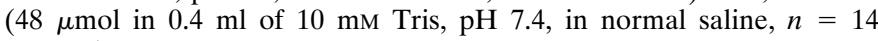
animals) was administered intravenously 15 min after TBI of $2.8 \mathrm{~atm}$. In our laboratory, TBI of $2.8 \mathrm{~atm}$ results in moderately severe injury, as revealed by behavioral and/or histological changes (Sun and Faden, 1995a,b). R,S-MCPG was obtained from Tocris Cookson. 


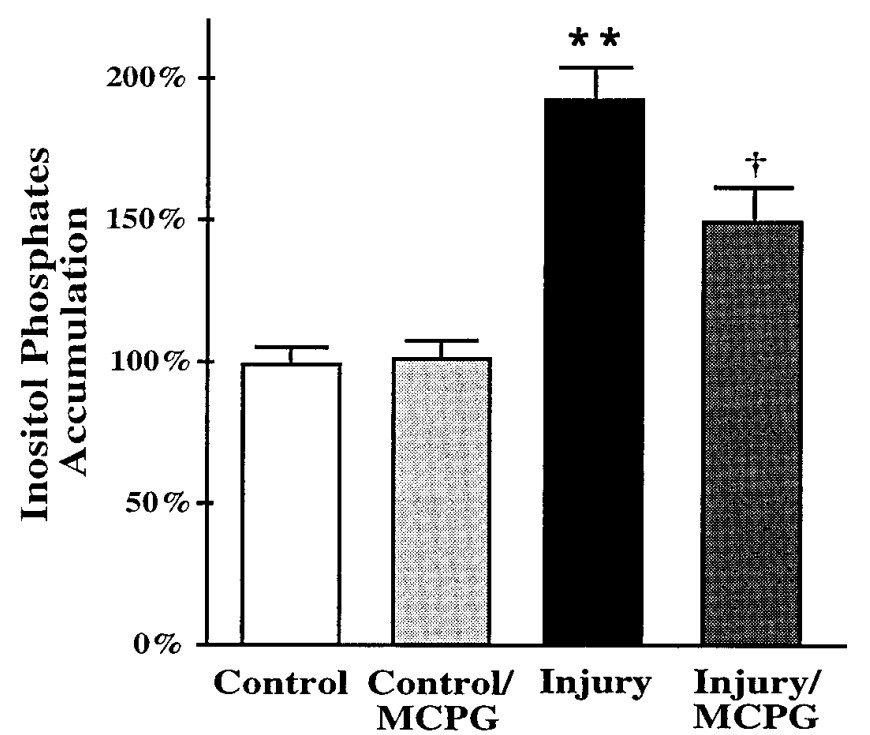

Figure 1. Trauma to mixed neuronal/glial cultures induced significant PI hydrolysis that was attenuated by treatment with an mGluR antagonist (500 $\mu \mathrm{M}$ MCPG added $30 \mathrm{~min}$ before injury). MCPG alone in control (uninjured) cultures had no significant effect on PI hydrolysis. PI hydrolysis was measured as accumulation of $\left[{ }^{3} \mathrm{H}\right]$ inositol phosphates from $5 \mathrm{~min}$ before and up to $30 \mathrm{~min}$ after injury. Data represent mean $\pm \mathrm{SEM} ; n=$ 16-22 cultures per condition. ** $p<0.01$ versus control (uninjured culture); ${ }^{\dagger}<0.05$ versus injury (untreated injury), using the StudentNewman-Keuls test after ANOVA.

Neurological scoring. Neuroscore tests included evaluation of resistance to lateral pulsion (right and left), forelimb contraflexion upon suspension by the tail (right and left), and ability to maintain position on an incline plane (right, left, vertical). These tests show high interobserver reliability and have been used by us in a number of studies to discriminate treatment effects (Faden et al., 1989; Sun and Faden, 1995a,b). Each test was rated from 0 (no function) to 5 (normal function); therefore, maximum composite score was 35 . Neuroscore tests were conducted by an individual unaware of treatment using procedures detailed previously (McIntosh et al., 1989; Sun and Faden, 1995a).

Cresyl violet staining. Two weeks after trauma, animals were anesthetized $(100 \mathrm{mg} / \mathrm{kg}$ sodium pentobarbital, i.p.) and perfused intracardially with heparinized saline (1 U/ml, Sigma) followed by $10 \%$ buffered formalin (Fisher Scientific, Fair Lawn, NJ). Brains were harvested, fixed for an additional $24 \mathrm{hr}$, cryoprotected in $10 \%$ sucrose in PBS, and frozen at $-80^{\circ} \mathrm{C}$ in embedding medium (Miles, Eckhart, IN). Coronal sections $(8$ $\mu \mathrm{m})$ from the dorsal hippocampus ( -2.2 to -3.8 relative to bregma) were thaw-mounted onto gelatin-rubbed slides and maintained at $-80^{\circ} \mathrm{C}$ for histological study. Sections were stained with Cresylecht Violet (Cellpoint Scientifica, Rockville, MD) and differentiated in ethanol and xylenes. The number of surviving neurons in the ipsilateral hippocampus was quantitated using light microscopy (Model BH2, Olympus) under 400× magnification by counting cells in areas CA1 and CA3 showing distinct nuclei and nucleoli (Sun and Faden, 1995b).

Data analysis. Data reflecting continuous variables were analyzed by Student-Newman-Keuls test after ANOVA or by Student's $t$ test for two-group comparisons. Neuroscore data were analyzed using the MannWhitney $U$ test after Kruskal-Wallis nonparametric ANOVA. $p<0.05$ was considered statistically significant.

\section{RESULTS}

\section{Activation of group I mGluR after mechanical injury}

To determine whether there was trauma-induced activation of PLC-coupled (group I) mGluR, we examined the effect of mechanical injury on accumulation of IP in the in vitro trauma model. In this model, mechanical injury to neuronal/glial cultures produced death in up to $60 \%$ of neurons $16-18 \mathrm{hr}$ after trauma. As demonstrated in Figure 1, mechanical trauma markedly increased

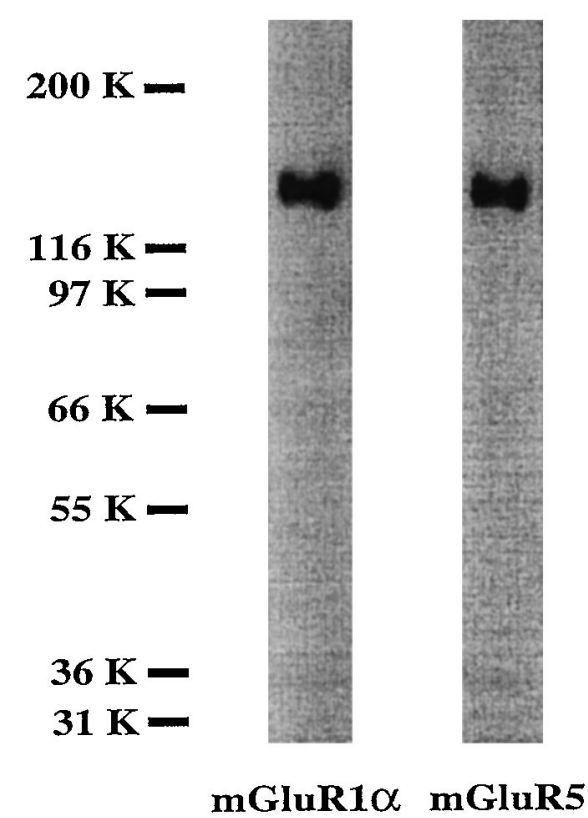

Figure 2. Both subtypes of PLC linked mGluR-mGluR1 (as mGluR1 $\alpha$ splicing variant) and mGluR5-are found in neuronal/glial cultures used in these studies. Cell membranes ( $8 \mu \mathrm{g}$ protein) were analyzed by SDSPAGE and immunoblotting with mGluR1 $\alpha$ - and mGluR5-specific antibodies, as described in Materials and Methods. When primary antibody was omitted from the incubation phase, the specific bands were not detected (data not shown). Data represent results of 18-DIV cell culture study; similar results were obtained in two additional experiments with 17and 20-DIV cultures.

IP accumulation $(p<0.01)$; this increase was significantly reduced $(p<0.05)$ by addition of $500 \mu \mathrm{M}$ MCPG. Because MCPG is an equipotential antagonist at mGluR groups I and II (Watkins and Collingridge, 1994; Pin and Duvoisin, 1995), and its effects on PLC are related to blockade of group I receptors (but not of group II receptors), these in vitro results suggest that traumatic injury activates group I mGluR.

\section{Immunodetection of group I mGluR subtypes in neuronal/glial cultures}

As noted above, group I mGluR includes two receptor subtypes: mGluR1 with four splicing variants and mGluR5 with two splicing variants. To evaluate the possible presence of group I mGluR specific subtypes in our neuronal/glial cultures, we used two available polyclonal antibodies, the first directed to the $\mathrm{C}$ terminus of one of the splicing variants of mGluR1 (mGluR1 $\alpha$ ), and the second directed to the $\mathrm{C}$ terminus of the splicing variants of mGluR5 (mGluR5 $\alpha$ and mGluR5 $\beta$ ) (Reid et al., 1995; Romano et al., 1995). As shown in Figure 2, each antibody recognizes only one specific band with a molecular weight of $\sim 140 \mathrm{kDa}$.

As was shown previously in an in vitro expression system, the mGluR $1 \alpha$ antibody used recognizes a specific $140 \mathrm{kDa}$ band in $\mathrm{CHO}$ cells transfected by mGluR $1 \alpha$ cDNA but not in cells transfected by mGluR5 $\alpha$ cDNA (J. Wroblewski, personal communication). Moreover, Romano et al. (1995) have reported that the mGluR5 antibody used by us does not cross-react with mGluR $1 \alpha$. Additional control experiments, in the absence of primary antibodies, showed a lack of cross-reactivity of the secondary antibody to cell culture membrane proteins (data not shown). 


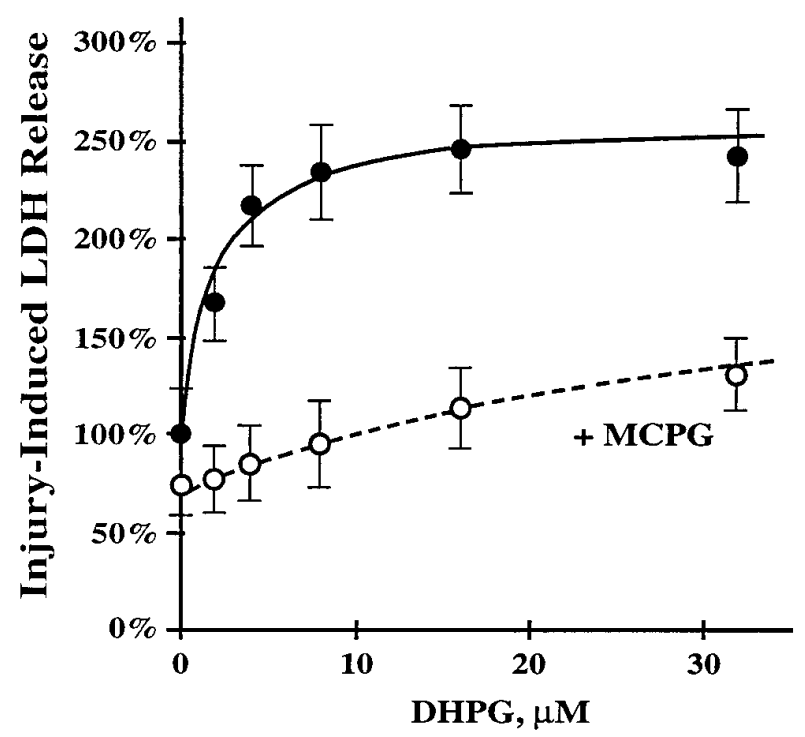

Figure 3. The agonist of group I mGluR DHPG in dose-dependent manner potentiates the injury-induced LDH release, which can be attenuated by the mGluR antagonist MCPG. Cultures were incubated in the presence of 2-32 $\mu \mathrm{M}$ DHPG (filled circles) or in the presence of 2-32 $\mu \mathrm{M}$ DHPG plus $1 \mathrm{~mm}$ MCPG (open circles) $30 \mathrm{~min}$ before and $30 \mathrm{~min}$ after injury. LDH levels were measured $16-18 \mathrm{hr}$ after injury. Data represent mean \pm SEM. DHPG alone: $n=19-20$ cultures for each concentration; DHPG plus MCPG: $n=10$ cultures for each concentration.

\section{Exacerbation of injury-induced neuronal death in vitro by DHPG, an agonist of group I mGluR}

To study the possible role of group I mGluR activation in exacerbating neuronal death caused by injury, we examined the effects of DHPG, a selective group I mGluR agonist (Schoeppet al., 1994) in the in vitro trauma system. As shown in Figure 3, DHPG produces a significant, dose-dependent increase of injury-induced LDH release that can be attenuated by MCPG. In control (uninjured) cultures, neither DHPG nor MCPG, nor a DHPG-MCPG combination, had any significant effect on $\mathrm{LDH}$ release (data not shown). These data indicate that activation of group I mGluR after trauma increases injury-induced neuronal death.

\section{Neuroprotective effects of group I mGluR antagonists in vitro}

In the same in vitro model, MCPG significantly decreased $(p<$ 0.01 ) trauma-induced $\mathrm{LDH}$ release (Fig. $4 A$ ), with $\mathrm{EC}_{50}=50-$ $100 \mu \mathrm{M}$ (Fig. 4B). As noted above, MCPG is an equipotential antagonist at mGluR groups I and II (Watkins and Collingridge, 1994; Pin and Duvoisin, 1995). To evaluate further the neuroprotective effect of group I mGluR blockade in traumatic injury, we also studied $4 \mathrm{CPG}$, which is a similar but more potent antagonist than MCPG at group I mGluR $\left(\mathrm{IC}_{50} \sim 30-40 \mu \mathrm{M}\right)$ and, only at much higher concentrations $\left(\mathrm{EC}_{50} \sim 500 \mu \mathrm{M}\right)$, is an agonist at group II mGluR (Watkins and Collingridge, 1994; Pin and Duvoisin, 1995). As shown in Figure 5, 4CPG-which is somewhat selective at group I receptors at the concentration used $(30 \mu \mathrm{M}$ vs $\mathrm{EC}_{50}$ on group II of $\left.500 \mu \mathrm{M}\right)$-also significantly decreased trauma-induced LDH release $(p<0.001)$. The fact that MCPG and 4 CPG have identical effects on group I receptors, yet opposite effects on group II receptors, suggests that each exerts neuroprotective action at group I receptors.

\section{Neuroprotective effects of MCPG in vivo}

To assess the role of mGluR in traumatic injury in vivo, we examined the effects of $R, S$-MCPG in an in vivo injury model using rats subjected to lateral fluid percussion-induced brain trauma. $R, S-\mathrm{MCPG}$ is an antagonist of group I and group II mGluR; other available group I antagonists show agonist activity at group II receptors. Because group II agonists show neuroprotective action (Bruno et al., 1994; Buisson and Choi, 1995; Buisson et al., 1996), we chose MCPG to exclude the possibility that suggested neuroprotective effects could be related to agonist action at group II receptors. $R, S$-MCPG administered intracerebroventricularly $15 \mathrm{~min}$ before and $1 \mathrm{hr}$ after trauma not only significantly improved neurological recovery $(p<0.01$; Fig. 6$)$ but also attenuated post-traumatic CA1 pyramidal cell loss $(p<0.01$, Student's $t$ test) in ipsilateral hippocampus (Fig. 7). Similar attenuation of cell loss was noted in CA3 (Fig. 7); however, it did not quite reach statistical significance ( $p<0.06$, Student's $t$ test).

In separate experiments designed to simulate more clinically relevant conditions, $R, S$-MCPG was given intravenously $15 \mathrm{~min}$ after trauma. MCPG-treated animals showed markedly enhanced neurological recovery compared with vehicle-treated controls at 1 week $(p<0.001)$ and at 2 weeks $(p<0.01)$ after TBI (Fig. 8).

\section{Neuroprotective effects of AS ODN directed to group I mGluR subtypes}

Recent in vitro expression studies (Brabet et al., 1995; Kingston et al., 1995) have shown that although 4 CPG is an antagonist to both mGluR1 subtypes, its potency is greater at mGluR1 receptor sites $\left(\mathrm{IC}_{50}=40-70 \mu \mathrm{M}\right)$ than at mGluR5 receptor sites $\left(\mathrm{IC}_{50}=\right.$ $150-2000 \mu \mathrm{M})$. The neuroprotective effect of $4 \mathrm{CPG}$ in our trauma model suggests the involvement of mGluR1 without definitively excluding the involvement of mGluR5. To address this point more directly, we examined the effects of pretreatment with AS ODN directed to mGluR1 or mGluR5 in vitro. Controls included cells treated with mismatched (missense) oligodeoxynucleotides (MS ODN) and sense oligodeoxynucleotides (S ODN). As shown in Figure 9, treatment with AS ODN directed to mGluR1 for $5 \mathrm{~d}$ significantly reduced post-traumatic neuronal death and associated LDH release $(p<0.01)$. In contrast, identical AS ODN treatment directed to mGluR5 had no appreciable effect on neuronal survival (Fig. 9). Injury-induced LDH release was nearly identical in cultures treated with MS ODN, S ODN, and untreated control cultures. Pretreatment alone with any of the ODN (in the absence of injury) caused no significant changes (data not shown). To determine the presence of both mGluR1 and mGluR5 subtypes in our cultures, and to demonstrate the efficacy of AS ODN treatment, we measured agonist-induced IP accumulation in uninjured cultures. AS ODN treatment directed to both mGluR1 and mGluR5 produced virtually identical reduction in $1 S, 3 R$-ACPD-induced IP accumulation ( $p<0.01$; Fig. 10). Therefore, the lack of neuroprotection with AS ODN treatment directed to mGluR5 did not appear to result from insufficient expression of mGluR5 or from failure of AS ODN to suppress translation of this receptor subtype.

\section{DISCUSSION}

Traumatic injuries to the CNS induce biochemical changes that contribute to irreversible tissue damage (Faden, 1993). This delayed autodestructive response, often referred to as "secondary injury," appears to involve a cascade of events that involves alterations in blood flow and metabolism, membrane damage with lipid hydrolysis, modifications in neurotransmitters/neuromodula- 
A

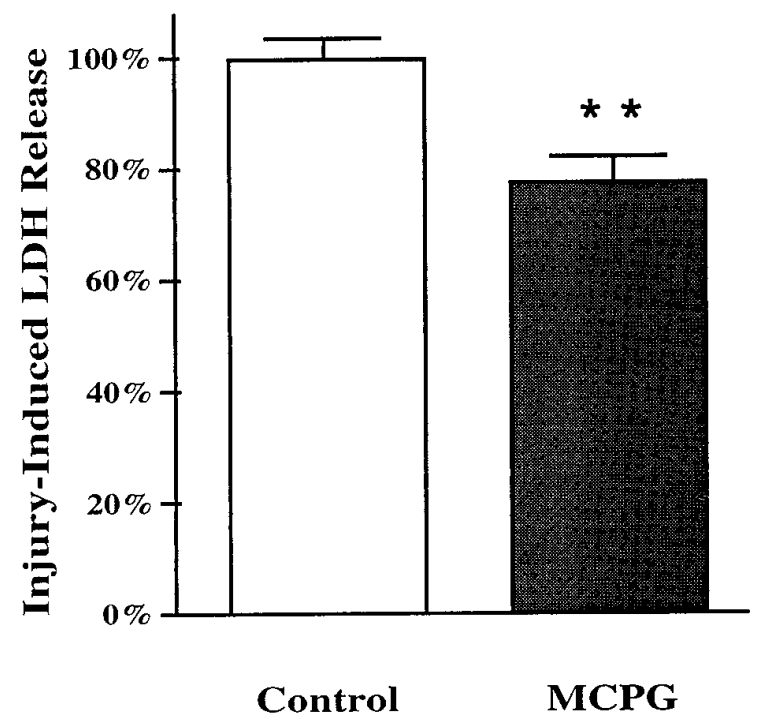

B

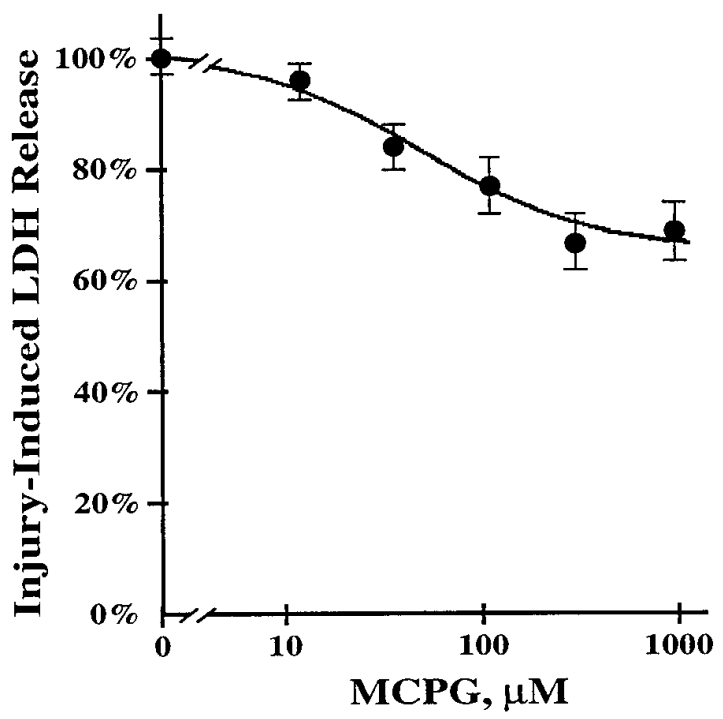

Figure 4. Treatment with MCPG attenuated neuronal injury after mechanical trauma to mixed neuronal/glial cultures, as reflected by changes in LDH release. Cultures were incubated in the absence or presence of $500 \mu \mathrm{M} \mathrm{MCPG}(A)$ or 12-1000 $\mu \mathrm{M} \mathrm{MCPG}(B) 30$ min before and 30 min after injury. LDH levels were measured $16-18 \mathrm{hr}$ after injury. Data represent mean \pm SEM. $A, n=25$ cultures per condition; $B, n=18-20$ cultures for each concentration; ${ }^{* *} p<0.01$ versus control (untreated injury) using Student's $t$ test.

tors and their receptors, changes in tissue content of monovalent and divalent cations, activation of free radical reactions and inflammatory/immune responses, among others (Faden, 1993; McIntosh, 1993; Panter and Faden, 1994).

TBI causes early (within $10 \mathrm{~min}$ ) release of glutamate into the extracellular space, which is highly correlated to injury severity (Faden et al., 1989; Katayama et al., 1990; Nilsson et al., 1990; Palmer et al., 1993). Treatment with NMDA antagonists reduces neuronal loss (Toulmond et al., 1993; Hicks et al., 1995) and improves behavioral recovery (Hayes et al., 1988; Faden et al.,

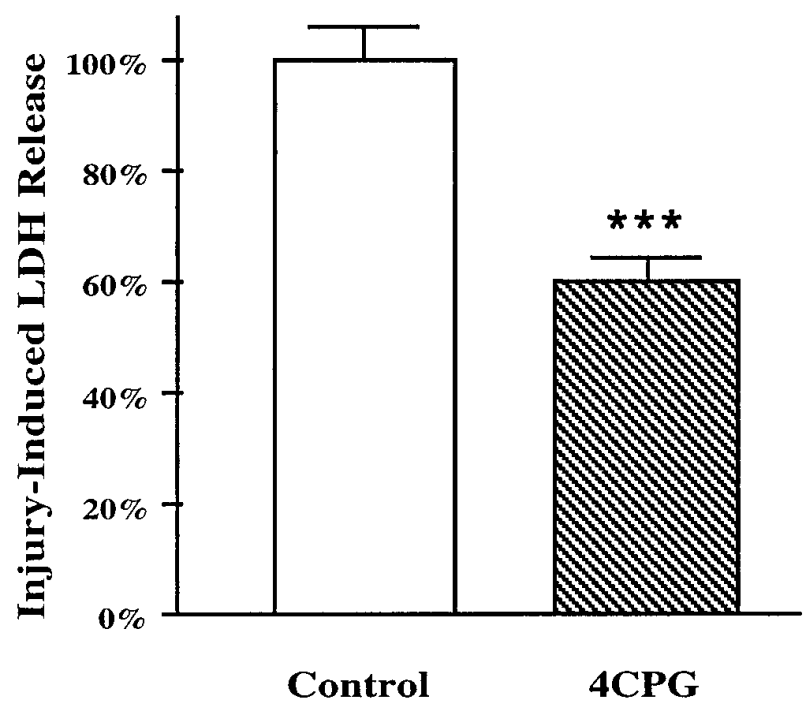

Figure 5. Treatment with $4 \mathrm{CPG}$, a somewhat selective antagonist at group I mGluR at the concentration used $(30 \mu \mathrm{M})$, also showed neuronal protection in vitro. Culture conditions, LDH measurements, and methods of drug administration were similar to those described in Figure 4. Data represent mean \pm SEM; $n=46-50$ cultures per condition. ${ }^{* * *} p<0.001$ versus control (untreated injury) using Student's $t$ test.
1989; Sharpira et al., 1990; McIntosh et al., 1993; Smith et al., 1993). Sun and Faden (1995a) have also shown that central administration of AS ODN directed to the NMDA-R1 subunit is neuroprotective. In addition, glutamate-release inhibitors, such as the sodium channel blockers BW1003C87 and 619C89, improve both behavioral and histological outcome after experimental brain trauma (Okiyama et al., 1995; Sun and Faden, 1995b).

Although the existence of metabotropic glutamate receptors

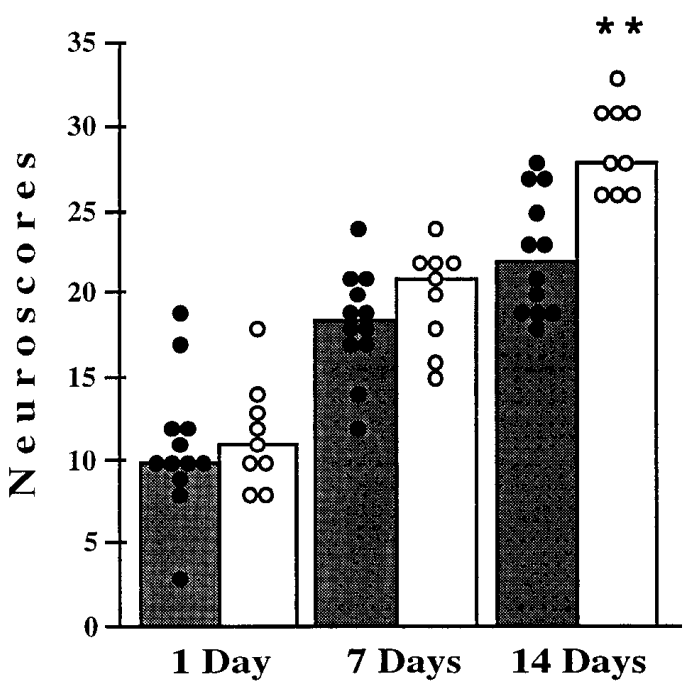

Figure 6. Intracerebroventricular administration of $R, S$-MCPG $(0.5$ $\mu \mathrm{mol} /$ injection) at $15 \mathrm{~min}$ before and $1 \mathrm{hr}$ after injury significantly improved neurological recovery after lateral fluid percussion-induced TBI in rats. Histograms represent median scores at different days post-trauma. Each circle represents individual animal cumulative neuroscore reflecting performance on a battery of motor tests. Filled circles, Untreated injury (vehicle), $n=12$ animals; open circles, injury treated by $R, S$-MCPG, $n=$ 9 animals. ${ }^{* *} p<0.01$ versus untreated injury (vehicle), using the MannWhitney $U$ test after Kruskal-Wallis nonparametric ANOVA. 


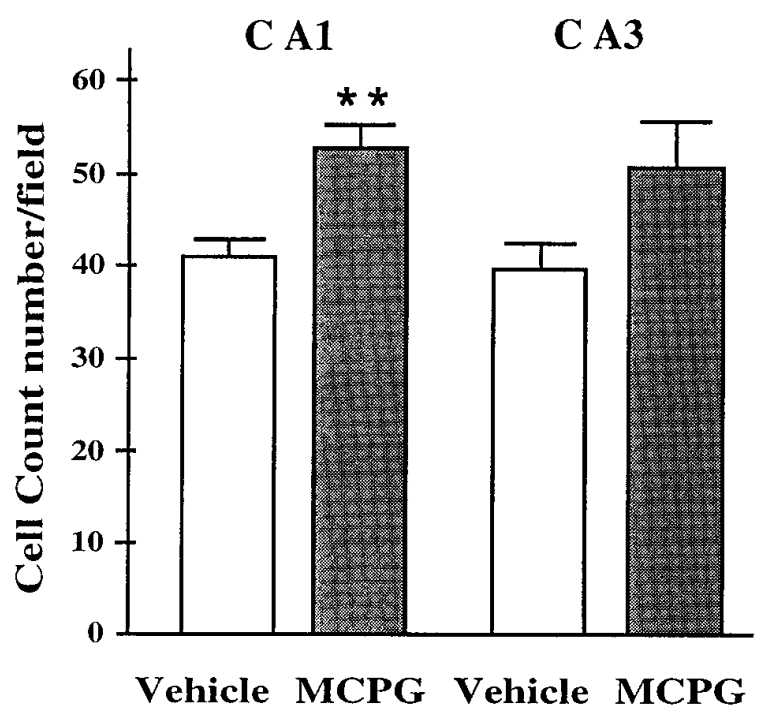

Figure 7. Intracerebroventricular administration of $R, S$-MCPG $(0.5$ $\mu \mathrm{mol} /$ injection) at $15 \mathrm{~min}$ before and $1 \mathrm{hr}$ after injury attenuated posttraumatic cell loss in ipsilateral hippocampus measured 2 weeks after fluid percussion-induced TBI. Cells were counted after staining $8 \mu \mathrm{m}$ coronal brain sections with cresyl violet. Data represent mean number of cells \pm SEM per $0.25 \times 0.25 \mathrm{~mm}$ field. Control group, $n=8$ animals; $R, S$-MCPGtreated group, $n=5$ animals. ${ }^{*} p<0.01$ versus control (untreated injury, vehicle) using Student's $t$ test.

was suggested in 1985 (Sladeczek et al., 1985), only the recent availability of somewhat selective agonists and antagonists has made it possible to address the potential pathophysiological roles for these receptors. Recent experimental studies have also indicated a possible, albeit inconsistent, action for metabotropic glutamate receptors in modulating neuronal death (Koh et al., 1991; Chiamulera et al., 1992; McDonald and Schoepp, 1992; Sacaan and Schoepp, 1992; Siliprandi et al., 1992; Birrell et al., 1993; McDonald et al., 1993; Bruno et al., 1994; Opitz et al., 1994; Gong et al., 1995; Buisson et al., 1996).

In the present studies, we demonstrated that DHPG, a specific agonist for group I mGluR (Schoepp et al., 1994), exacerbated trauma-induced neuronal cell death in tissue culture in a dosedependent manner. Effects of DHPG were markedly attenuated by MCPG, an antagonist of group I/II mGluR. These results are in agreement with the findings of Buisson and Choi (1995), who showed that the group I receptor agonist $3 \mathrm{HPG}$ promoted neuronal death in culture after oxygen-glucose deprivation or after brief NMDA exposure. Like other investigators using in vitro models to examine injury (Koh and Choi, 1987; Regan and Choi, 1994), we used LDH release as a marker of cell death, based on studies showing that $\mathrm{LDH}$ increase is highly correlated with the percentage of nonviable neurons, as evidenced by trypan blue staining and other methods (Regan and Choi, 1994) (our unpublished data). Although the mechanism leading to $\mathrm{LDH}$ release after injury is not fully understood, it may reflect damage to cell membranes (Koh and Choi, 1987). In our experiments, treatment of cultures with DHPG alone, at doses that exacerbate traumainduced cell loss (up to $32 \mathrm{~mm}$ ), did not appear to be associated with neuronal death. These observations suggest that activation of group I mGluR, rather than exerting a direct action, may in fact trigger secondary injury mechanisms. For example, group I mGluR activation enhances the activity of NMDA receptors (Fitzjohn et al., 1996), thereby potentiating post-traumatic excitotoxicity mediated by those receptors (Faden et al., 1989). In this

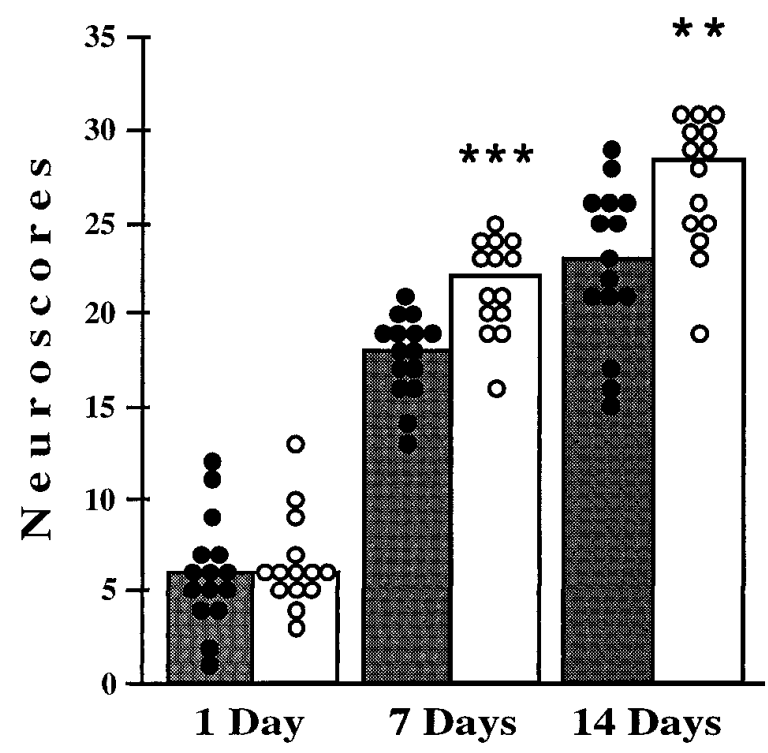

Figure 8. Intravenous administration of $48 \mu \mathrm{M} R, S$-MCPG $15 \mathrm{~min}$ after injury significantly improved neurological recovery at 1 and 2 weeks after lateral fluid percussion-induced TBI in rats. Histograms represent median scores at different days post-trauma. Each circle represents individual animal cumulative neuroscore. Filled circles, Untreated injury (vehicle), $n=15$ animals: open circles, injury treated by $R, S-\mathrm{MCPG}, n=14$ animals. $* * p<0.01$; ***p $<0.001$ versus untreated injury (vehicle), using the Mann-Whitney $U$ test after Kruskal-Wallis nonparametric ANOVA.

respect, it should be noted that in our in vitro model, treatment with the NMDA receptor antagonist MK-801 reduced cell death by up to $60 \%$ (Mukhin and Faden, 1995).

The fact that pharmacological blockade of group I mGluR decreases trauma-induced PI hydrolysis and neuronal loss in vitro indicates that traumatic injury, in addition to activating NMDA receptors in this model, also activates phospholipase C-linked mGluR. Recent studies have demonstrated that fluid-percussion TBI in rats causes PI hydrolysis (Prasad et al., 1994). Another laboratory (Delahunty et al., 1992) studied muscarinic or metabotropic agonist-stimulated PI hydrolysis in rat hippocampus and found a greater response in hippocampi of traumatized animals. These data are consistent with our findings regarding the participation of PLC, particularly mGluR-linked PLC, in TBI.

In our in vitro model, MCPG and $4 \mathrm{CPG}$ produced similar neuroprotective actions. These data are compatible with the observation of Opitz et al. (1994) that MCPG is neuroprotective in hippocampal slices subjected to hypoxia/hypoglycemia. Whereas MCPG is an equipotential antagonist of both group I and group II mGluR, 4CPG is a relatively selective group I antagonist at the concentrations used, and only at higher concentrations does it exert agonist activity at group II receptors (Pin and Duvoisin, 1994; Watkins and Collingridge, 1994). Taken together, these data support our hypothesis that the neuroprotective actions of these compounds result from blockade of group I mGluR. A role for group I mGluR in post-traumatic neuronal death is also strongly supported by our findings that AS ODN directed to the mGluR1 receptor subtype has a neuroprotective effect. This conclusion is reinforced further by results of our experiments using the group I receptor agonist DHPG.

Beneficial effects were also observed for $R, S$-MCPG after in vivo trauma; this compound, given centrally (i.c.v.), improved neurological recovery and survival of hippocampal neurons. These findings agree with recent work by Gong et al. (1995), which 


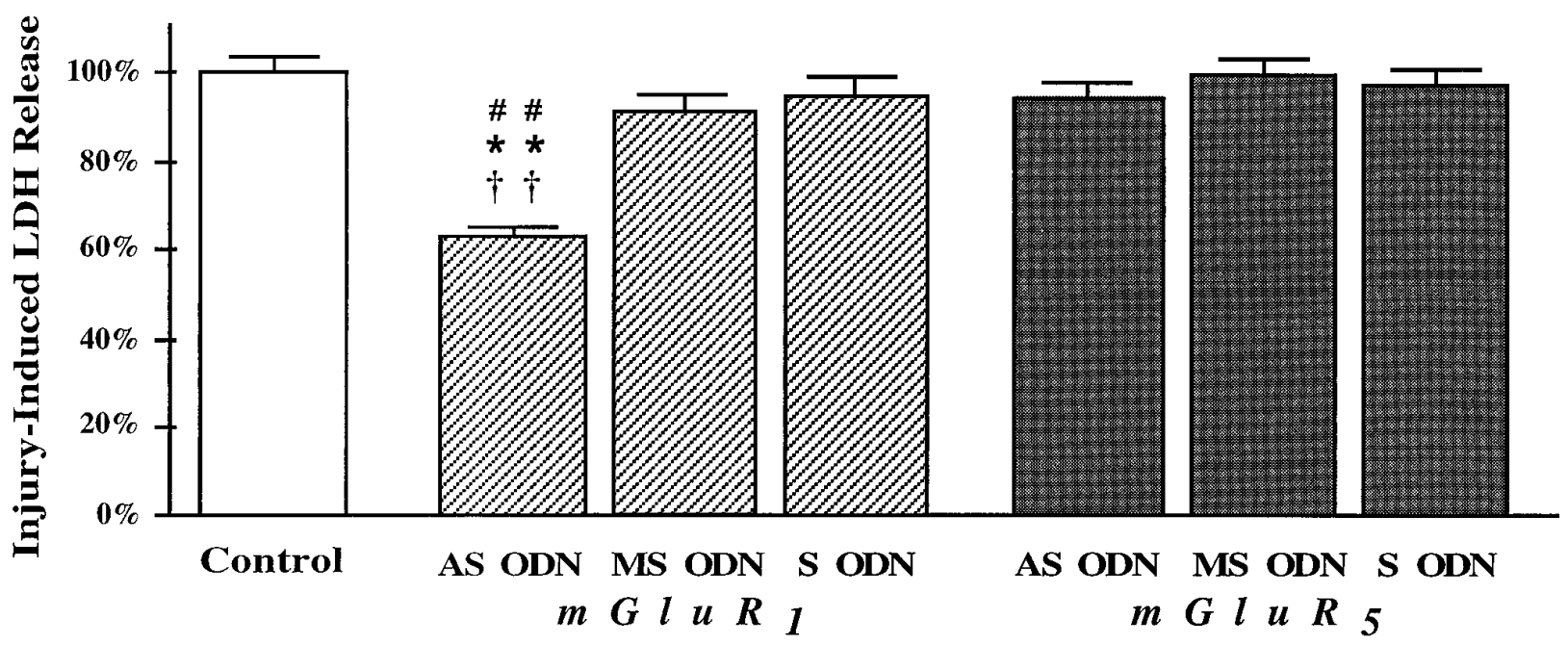

Figure 9. Pretreatment with AS ODN directed to mGluR1, but not AS ODN directed to mGluR5, significantly reduced neuronal death after trauma in vitro. Treatment with mismatched (missense) MS ODN or with sense ODN (S ODN) had no significant effect on neuronal survival. Neuronal/glial cultures were treated with $2 \mu \mathrm{M}$ appropriate ODN for $5 \mathrm{~d}$. Neuronal death was evaluated as injury-induced LDH release 16-18 hr after injury. Data represent mean \pm SEM; $n=30-40$ cultures per condition. Multiple comparisons were performed using ANOVA and Student-Newman-Keuls test: ${ }^{* *} p<0.01$ versus control (untreated injury); ${ }^{\dagger \dagger} p<0.01$ versus MS ODN treatment; ${ }^{\# \#} p<0.01$ versus S ODN treatment.

showed that pretreatment with MCPG, administered intracerebroventricularly in rats before fluid percussion-induced TBI, improved certain motor and memory tasks. By themselves, these in vivo results do not permit a definitive conclusion about the participation of group I mGluR in post-traumatic neuronal death because of the mixed pharmacological profile of MCPG. However, in vitro studies indicate that activation of group II mGluR is neuroprotective (Bruno et al., 1992), and that this neuroprotective effect is diminished by MCPG (Choi, 1996). Thus, studies using both in vivo and in vitro models appear to implicate group I mGluRs. Additional in vivo studies with more selective mGluR antagonists or with AS ODN are needed to confirm this conclusion. It should be noted that, in separate in vivo studies, we demonstrated protective effects for MCPG, even when administered systemically (i.v.), after trauma. These results indicate that group I mGluR antagonists may have therapeutic potential in the treatment of brain trauma.

In our in vitro studies, treatment with AS-ODN directed to mGluR1, but not treatment with AS-ODN directed to mGluR5, improved postinjury neuronal survival in our cultures. As we have shown, both mGluR1 and mGluR5 receptor subtypes can be detected by immunoblotting in our cultures. We have also found that AS ODN directed to either mGluR1 or mGluR5 decreased $1 S, 3 R$-ACPD-induced PI hydrolysis to similar levels. These findings suggest that the lack of neuroprotective effect of AS-ODN treatment directed to mGluR5 results neither from insufficient expression of mGluR5 nor from failure of AS ODN to suppress translation of this receptor subtype.

There are several possible explanations for the lack of neuroprotective effect of AS ODN at mGluR5 receptors. mGluR1 and

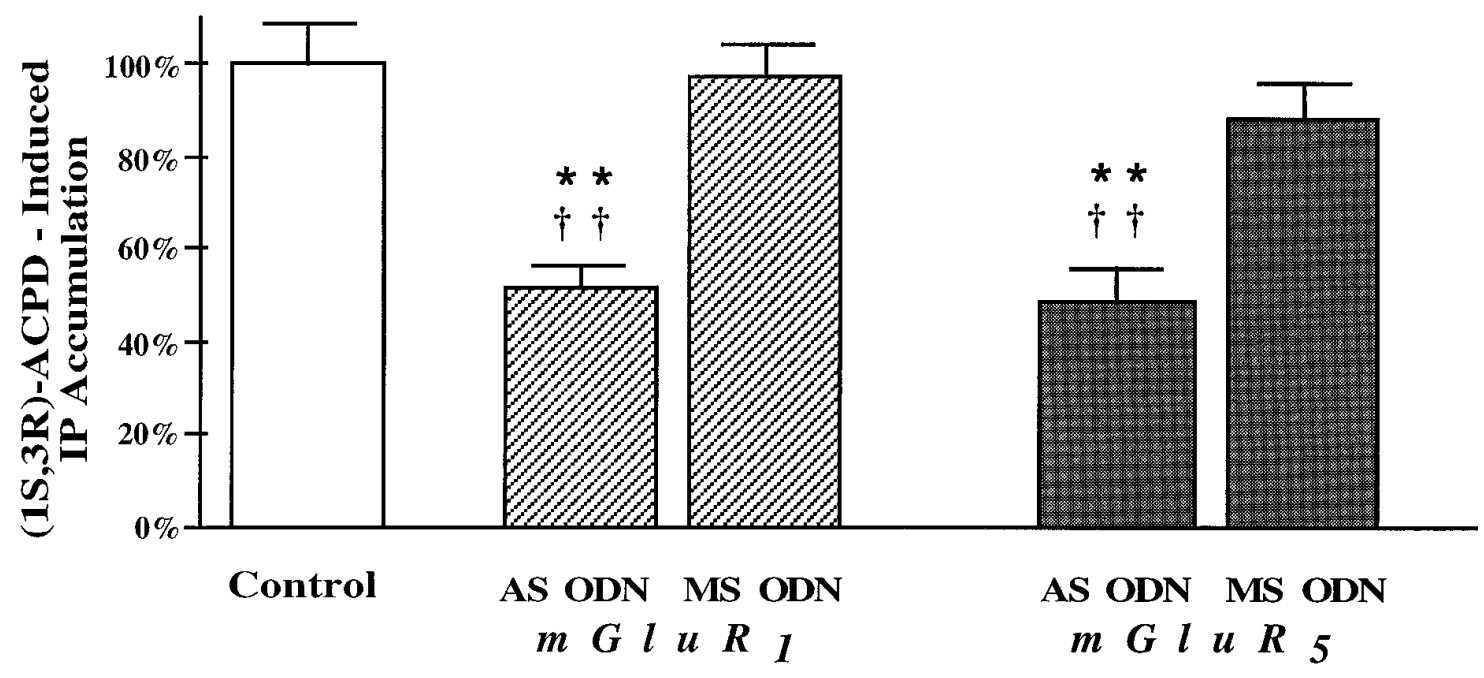

Figure 10. Pretreatment with AS ODN directed to mGluR1 as well as pretreatment with AS ODN directed to mGluR5 significantly reduced $1 S, 3 R$-ACPD-induced PI hydrolysis. Treatment with mismatched (missense) ODN had no significant effect on $1 S, 3 R$-ACPD-induced PI hydrolysis. PI hydrolysis was measured as inositol phosphate $(I P)$ accumulation within $30 \mathrm{~min}$ after addition of $500 \mu \mathrm{M} 1 S, 3 R$-ACPD. Data represent mean \pm SEM; $n=$ $30-40$ cultures per condition. Multiple comparisons were performed using ANOVA and Student-Newman-Keuls test. ** $p<0.01$ versus control (untreated injury); ${ }^{\dagger \dagger} p<0.01$ versus MS ODN treatment. 
mGluR5 may not be activated to the same degree by injury. For example, mGluR5 may not be the predominant receptor subtype in synapses activated after injury, or mGluR5 may be expressed by cell types, such as glia, which are less susceptible to traumainduced cell death. Another explanation may be the differences in the signal transduction pathways activated by each receptor subtype. Whereas activation of both receptors causes stimulation of PLC activity, mGluR1 may additionally mediate increases in phospholipase A2 and/or adenylyl cyclase activity (Pin and Duvoisin, 1995). More studies will be necessary to address this issue. Taken together, our in vivo and in vitro studies show that activation of group I mGluR, particularly mGluR1, contributes to the pathophysiology of post-traumatic neuronal death. These observations further suggest that more selective mGluR1 antagonists may prove to have therapeutic utility.

\section{REFERENCES}

Abe T, Sugihara H, Nawa H, Shigemoto R, Mizuno N, Nakanishi S (1992) Molecular characterization of a novel metabotropic glutamate receptor mGluR5 coupled to inositol phosphate $/ \mathrm{Ca}^{2+}$ signal transduction. J Biol Chem 267:13361-13368.

Amador E, Dorfman LE, Wacher WEC (1963) Serum lactate dehydrogenase activity: an analytical assessment of current assays. Clin Chem 9:391-399.

Berridge MJ, Downes CP, Hanley MR (1982) Lithium amplifies agonistdependent phosphatidylinositol responses in brain and salivary glands. Biochem J 206:587-595.

Birrell GJ, Gordon MP, Marcoux FW (1993) (1S,3R)-1-Aminocyclopentane1,3-dicarboxylic acid attenuates $N$-methyl-D-aspartate-induced neuronal cell death in cortical cultures via a reduction in delayed $\mathrm{Ca}^{2+}$ accumulation. Neuropharmacology 32:1351-1358.

Brabet I, Mary S, Bockaert J, Pin J-P (1995) Phenylglycine derivatives discriminate between mGluR1- and mGluR5-mediated responses. Neuropharmacology 34:895-903.

Bruno V, Copani A, Battagli G, Raffaele R, Shinozaki H, Nicoletti F (1994) Protective effect of the metabotropic glutamate receptor agonist, DCG-IV, against excitotoxic neuronal death. Eur J Pharmacol 256:109-112.

Buisson A, Choi DW (1995) The inhibitory mGluR agonist, $S$-4-carboxy3-hydroxy phenylglycine selectively attenuates NMDA neurotoxicity and oxygen-glucose deprivation-induced neuronal death. Neuropharmacology 34:1081-1087.

Buisson A, Yu SP, Choi DW (1996) DCG-IV selectively attenuates rapidly triggered NMDA-induced neurotoxicity in cortical neurons. Eur J Neurol 8:138-143.

Chiamulera C, Albertini P, Valerio E, Reggiani A (1992) Activation of metabotropic receptors has a neuroprotective effect in a rodent model of focal ischaemia. Eur J Pharmacol 216:335-336.

Delahunty TM (1992) Mild traumatic brain injury enhances muscarinic receptor-linked inositol phosphate production in rat hippocampus. Brain Res 594:307-310.

Faden AI, Simon RP (1988) A potential role for excitotoxins in the pathophysiology of spinal cord injuries. Ann Neurol 23:623-626.

Faden AI (1993) Experimental neurobiology of central nervous system. Crit Rev Neurobiol 7:175-186.

Faden AI, Demediuk P, Panter Vink R (1989) The role of excitatory amino acids and NMDA receptors in traumatic brain injury. Science 244:98-800.

Fitzjohn SM, Irving AJ, Palmer MJ, Harvey J, Lodge D, Collingridge GL (1996) Activation of group I mGluRs potentiates NMDA responses in rat. Neurosci Lett 203:211-213.

Gong QZ, Delahunty TM, Hamm RJ, Lyeth BG (1995) Metabotropic glutamate antagonist (MCPG) treatment of traumatic brain injury in rats. Brain Res 700:299-302.

Hayes RL, Jenkins LW, Lyeth BG, Bulster RL, Robinson SE, Clifton GL (1988) Pretreatment with phencyclidine, an $N$-methyl-D-aspartate antagonist, attenuates long-term behavioral deficits in the rat produced by traumatic brain injury. J Neurotrauma 5:259-274.

Hicks RR, Smith DH, McIntosh TK (1995) Temporal response and effects of excitatory amino acid antagonism on microtubule-associated protein 2 immunoreactivity following experimental brain injury in rats. Brain Res 678:151-160.
Hollmann M, Heinemann S (1994) Cloned glutamate receptors. Annu Rev Neurosci 17:31-108.

Katayama Y, Becker DP, Tamura T, Hovda DA (1990) Massive increases in extracellular potassium and the indiscriminate release of glutamate following concussive brain injury. J Neurosurg 73:889-900.

Kingston AE, Burnett JP, Mayne NG, Lodge D (1995) Pharmacological analysis of 4-carboxyphenyl derivatives: comparison of effects of mGluR1 $\alpha$ and mGluR5 $\alpha$ subtypes. Neuropharmacology 34:887-894.

Koh JY, Choi DW (1987) Quantitative determination of glutamate mediated cortical neuronal injury in cell culture by lactate dehydrogenase efflux assay. J Neurosci Methods 20:83-90.

Koh JY, Palmer E, Cotman C (1991) Activation of the metabotropic glutamate receptor attenuates $N$-methyl-D-aspartate neurotoxicity in cortical cultures. Proc Natl Acad Sci USA 88:9431-9435.

Masu M, Tanabe Y, Tsuchida K, Shigemoto R, Nakanishi S (1991) Sequence and expression of a metabotropic glutamate receptor. Nature 349:760-765.

McDonald JW, Schoepp DD (1992) The metabotropic excitatory amino acid receptor agonist $1 S, 3 R$-ACPD selectively potentiates $N$-methyl-Daspartate-induced brain injury. Eur J Pharmacol 215:353-354.

McDonald JW, Fix AS, Tizzano JP, Schoepp DD (1993) Seizures and brain injury in neonatal rats induced by $1 S, 3 R$-ACPD, a metabotropic glutamate receptor agonist. J Neurosci 13:4445-4455.

McIntosh TK (1993) Novel pharmacologic therapies in the treatment of experimental traumatic brain injury: a review. J Neurotrauma $10: 215-261$.

McIntosh TK, Vink R, Noble L, Yamakami S, Fernyak S, Soares H, Faden AI (1989) Traumatic brain injury in the rat: characterization of a lateral fluid-percussion model. Neuroscience 28:233-244.

McIntosh TK, Vink R, Soares H, Hayes R, Simon R (1990) Effect of non-competitive blockade of $N$-methyl-D-aspartate receptors on the neurochemical sequelae of experimental brain injury. J Neurochem 55:1170-1179.

McIntosh TK, Soares HL, Hayes RL, Simon RP (1993) The $N$-methylD-aspartate antagonist MK-801 prevents edema and restores magnesium homeostasis following traumatic brain injury in rats. In: Recent advances in excitatory amino acid research (Leahman J, ed), pp 653656. New York: Liss.

Mukhin AG, Faden AI (1995) pH dependence of neuronal cell death and $\mathrm{Ca}^{2+}$ influx after traumatic injury in rat cortical coculture. Soc Neurosci Abstr 21:764.

Nilsson P, Hillered L, Ponten U, Ungerstedt U (1990) Changes in cortical extracellular levels of energy-related metabolites and amino acids following concussive brain injury in rats. J Cereb Blood Flow Metab 10:631.

Okiyama K, Smith DH, Gennarelli TA, Simon RP, Leach M, McIntosh TK (1995) The sodium channel blocker and glutamate release inhibitor BW1003C87 and magnesium attenuate regional cerebral edema following experimental brain injury in the rat. J Neurochem 64:802-809.

Opitz T, Richter R, Reymann KG (1994) The metabotropic glutamate receptor antagonist $(+)$ - $\alpha$-methyl-4-carboxyphenylglycine protects hippocampal CA1 neurons of the rat from in vitro hypoxia/hypoglycemia. Neuropharmacol 33:715-717.

Palmer AM, Marion DW, Botscheller ML, Swedlow PE, Styren SD, DeKosky ST (1993) Traumatic brain injury-induced excitotoxicity assessed in a controlled cortical impact model. J Neurochem 61:2015-2024.

Panter SS, Faden AI (1994) Biochemical changes and secondary injury from stroke and trauma. In: Principles and practice of restorative neurology (Young RR, Delawade PJ, eds), pp 32-52. New York: Butterworth.

Pin J-P, Duvoisin R (1995) Review: neurotransmitter receptors I-the metabotrobic glutamate receptors: structure and functions. Neuropharmacology 34:1-26.

Pin J-P, Fagni L, Bockaert J (1993) The metabotropic glutamate receptors: targets for new pharmacologically active drugs. Curr Drugs Neurodegenerative Dis 1:111-137.

Prasad MR, Dhillon HS, Carbary T, Dempsey RJ, Scheff SW (1994) Enhanced phosphodiestric breakdown of phosphatidylinositol biphosphate after experimental brain injury. J Neurochem 63:773-776.

Regan RF, Choi DW (1994) The effect of NMDA, AMPA-kainate, and calcium channel antagonist on traumatic cortical neuronal injury in culture. Brain Res 633:236-242.

Reid SNM, Romano C, Hughes T, Daw NW (1995) Immunohistochemical study of two phosphoinositide-linked metabotropic glutamate receptors (mGluR1 $\alpha$ and mGluR5) in the cat visual cortex before, during, 
and after the peak of the critical period for eye-specific connections. J Comp Neurol 355:470-477.

Romano C, Sesma MA, McDonald CT, O'Malley K, Van Den Pol AN, Olney JW (1995) Distribution of metabotropic glutamate receptor mGluR5 immunoreactivity in rat brain. J Comp Neurol 355:455-469.

Sacaan AI, Schoepp DD (1992) Activation of hippocampal metabotropic excitatory amino acid receptors leads to seizures and neuronal damage. Neurosci Lett 139:77-82.

Saugstad JA, Kinzie JM, Mulvihill ER, Segerson TP, Westbrook GL (1994) Cloning and expression of a new member of the L-2-amino-4phosphonobutyric acid-sensitive class of metabotropic glutamate receptors. Mol Pharmacol 45:367-372.

Saugstad JA, Segerson TP, Westbrook GL (1995) L-2-Amino-3phosphonopropionic acid competitively antagonizes metabotropic glutamate receptors 1 alpha and 5 in Xenopus oocytes. Eur J Pharmacol 289:395-397.

Schoepp DD, Conn PJ (1993) Metabotropic glutamate receptors in brain function and pathology. Trends Pharmacol Sci 14:13-20.

Schoepp DD, Goldsworthy J, Johnson BG, Salhoff CR, Baker SR (1994) 3,5-Dihydroxyphenylglycine is a highly selective agonist for phosphoinositide-linked metabotropic glutamate receptors in the rat hippocampus. J Neurochem 63:769-772.

Sharpira Y, Yadid C, Cotev A, Niska A, Shohami E (1990) Protective effect of MK-801 in experimental brain trauma. J Neurotrauma 1:131-139.

Siliprandi R, Lipartiti M, Fadda E, Sautter J, Manev H (1992) Activation of the glutamate metabotropic receptor protects retina against $N$-methyl-D-aspartate toxicity. Eur J Pharmacol 219:173-174.
Sladeczek F, Pin J-P, Récasens M, Bockaert J, Weiss S (1985) Glutamate stimulates inositol phosphate formation in striatal neurons. Nature 317:717-719.

Smith DH, Okiyama K, Thomas MJ, McIntosh TK (1993) Effects of the excitatory amino acid receptor antagonists kynurenate and indole-2carboxylic acid on behavioral and neurochemical outcome following experimental brain injury. J Neurosci 13:5383-5392.

Sun F-Y, Faden AI (1995a) Pretreatment with antisense oligodeoxynucleotides directed against the NMDA-R1 receptor enhances survival and behavioral recovery following traumatic brain injury in rats. Brain Res 693:163-168.

Sun F-Y, Faden AI (1995b) Neuroprotective effects of 619C89, a usedependent sodium channel blocker, in rat traumatic brain injury. Brain Res 673:133-140.

Tecoma ES, Monyer H, Goldberg MP, Choi DW (1989) Traumatic neuronal injury in vitro is attenuated by NMDA antagonists. Neuron 2:1541-1545.

Toulmond S, Serrano A, Benavides J, Scatton B (1993) Prevention by eliprodil (SL 82,0715) of traumatic brain damage in the rat: existence of a large (18 hr) therapeutic window. Brain Res 620:32-41.

Watkins J, Collingridge G (1994) Review: phenylglycine derivatives as antagonists of metabotropic receptors. Trends Pharmacol Sci 15:333-342.

Wrathall JR, Teng YD, Choiniere D, Mundt DJ (1992) Evidence that local non-NMDA receptors contribute to functional deficits in contusive spinal cord injury. Brain Res 586:140-143. 